\title{
EDUCACÃO
}

\section{Narrativas e histórias de mulheres negras ex-cotistas do curso de Pedagogia}

\author{
Kelly da SILVA ${ }^{1}$ \\ Anderson FERRARI ${ }^{2}$
}

\begin{abstract}
Resumo
Este artigo traz as narrativas, às histórias e às experiências de cinco mulheres professoras negras do curso de Pedagogia da Universidade do Estado de Minas Gerais (UEMG) e que respondem à questão: como se constituíram como professoras? A trajetória escolar das entrevistadas até o Ensino Médio demonstra que elas sofreram violência, discriminação e preconceito racial desde a Educação Infantil. Algumas citaram a importância das políticas de ações afirmativas e a necessidade de que os professores estejam capacitados para lidar com a temática em sala de aula e em todo ambiente escolar. Para coleta de dados, foram realizadas entrevistas semiestruturadas buscando as memórias da trajetória de formação fundamentadas na perspectiva pós-estruturalista com inspiração em Michel Foucault e sua análise histórica dos sujeitos.
\end{abstract}

Palavras-chaves: Gênero. Narrativas. História. Mulheres negras. Educação.

\footnotetext{
${ }^{1}$ Licenciatura em Pedagogia pela UFV, Mestra e Doutora em Educação pela UFJF. Professora da UEMG-Ubá. Coordenadora do Grupo de Pesquisa Núcleo de Estudos em Reafirmação Afrodescendente (NERA), ORCID: http://orcid.org/0000-0001-6092-8749. Email: kelly.silva@uemg.br

${ }^{2}$ Licenciado e Bacharel em História pela UERJ, Mestre em Educação pela UFJF e Doutor pela Unicamp. Professor da UFJF, professor permanente do PPGE/UFJF, Coordenador do Grupo de Estudos e Pesquisas em Gênero, Sexualidade, Educação e Diversidade (GESED/UFJF). ORCID: http://orcid.org/0000-0002-5681-0753. E-mail: aferrari13@globo.com
} 


\title{
Narratives and stories of black women ex-quota holders of the Pedagogy course
}

Kelly da SILVA

Anderson FERRARI

\begin{abstract}
This text brings the narratives that give materiality to the stories and experiences of five black female quota teachers from the Pedagogy course at the State University of Minas Gerais (UEMG) and that answer the question: how were they constituted as teachers? The educational trajectory of the interviewees up to High School demonstrates that they have suffered violence, discrimination and racial prejudice since Kindergarten. Some mentioned the importance of affirmative action policies and the need for teachers to be trained to deal with the topic in the classroom and in the entire school environment. For data collection, semistructured interviews were carried out seeking the memories of the formation trajectory based on the post-structuralist perspective inspired by Michel Foucault and his historical analysis of the subjects.
\end{abstract}

Keywords: Gender. Narratives. Story. Black women. Education. 


\title{
Narrativas y historias de mujeres negras ex-cuotistas del curso de Pedagogía
}

Kelly da SILVA

Anderson FERRARI

\begin{abstract}
Resumen
Este artículo trae las narrativas, las historias y las vivencias de cinco maestras negras del curso de Pedagogía de la Universidad Estatal de Minas Gerais (UEMG) y que responden a la pregunta: ¿cómo se constituyeron como docentes? La trayectoria educativa de las entrevistadas hasta el Bachillerato demuestra que han sufrido violencia, discriminación y prejuicios raciales desde el jardín de infancia. Algunas mencionaron la importancia de las políticas de acción afirmativa y la necesidad de capacitar a los docentes para abordar el tema en el aula y en todo el entorno escolar. Para la recolección de datos, se realizaron entrevistas semiestructuradas buscando los recuerdos de la trayectoria de formación a partir de la perspectiva postestructuralista inspirada en Michel Foucault y su análisis histórico de los sujetos.
\end{abstract}

Palabras clave: género. Narrativas. Historia. Mujeres negras. 


\section{Introdução}

Este artigo é resultado de uma pesquisa mais abrangente na área da Educação interessada na inserção histórica de mulheres negras na Universidade pelo sistema de cotas e seus desdobramentos no contexto da sala de aula. O trabalho foi realizado com egressas cotistas do Curso de Pedagogia da Faculdade de Educação da Universidade do Estado de Minas Gerais (UEMG), campus Belo Horizonte. A UEMG implementou o sistema de cotas no ano de 2004, sendo uma das primeiras universidades públicas a adotar essa política. As estudantes que ingressaram nessa primeira turma concluíram sua formação inicial entre os anos de 2008 e 2009 e, atualmente, encontram-se em sala de aula no exercício da docência. Entre os 12 contemplados pelo sistema de cotas, oito eram mulheres e quatro homens, sendo que todas e todos concluíram o curso. Dessas oito mulheres ex-cotistas, trabalhamos com cinco que aceitaram o convite para participar da pesquisa e que, atualmente, são professoras em escolas públicas de Belo Horizonte ou região. Todas se identificaram como negras, sendo as primeiras da família a ingressar no curso superior, tendo hoje idades que variam de 32 a 47 anos.

Nossas questões de investigação eram aquelas que diziam das relações dessas mulheres com a formação na Universidade e os efeitos nos seus modos de subjetivação e na constituição como professoras negras. Como essas mulheres acessaram a Universidade? Quais suas trajetórias de escolarização? Quais os efeitos dessa formação nas suas práticas atuais? Conhecer a trajetória dessas mulheres significa reconhecer e analisar, historicamente, os avanços e as conquistas do Movimento Negro na vida da população negra, assim como os desafios e as potencialidades ainda existentes para as temáticas de gênero e raça. O debate em torno da inserção das primeiras mulheres negras num curso de formação em Pedagogia diz de uma perspectiva histórica de construção do combate ao racismo no Brasil, de maneira que queremos problematizar as relações de gênero na interseccionalidade com a raça. No campo da Educação, esse debate passa pela formação docente e envolve as questões históricas de constituição das populações negras.

Sobre os caminhos da pesquisa, consideramos importante destacar que é o referencial teórico pósestruturalista que orienta nossas análises, principalmente a influência do arcabouço de Michel Foucault para essa perspectiva teórico-metodológica. Guacira Lopes Louro (2006), no desafio de esclarecer o que significa fazer pesquisa em gênero, sexualidade e educação na perspectiva pós-estruturalista, provoca-nos a pensar que a forma como escrevemos declara como pensamos e conhecemos. Nesse sentido, nosso entendimento de gênero está centrado na historicidade desse conceito, na sua construção como resultado de disputa discursiva, atravessado por relações de saber-poder (FOUCAULT, 1988). Com isso, queremos afirmar que o pós-estruturalismo é uma perspectiva de análise histórica que se amplia para o entendimento de raça, negando o caráter de essência ou algo natural tanto para as relações de gênero quanto para as questões raciais.

Assim, buscamos problematizar como as egressas cotistas constroem suas identidades como professoras e como o fazer-se professora diz de um processo contínuo que antecede a entrada na graduação e passa pelas questões do exercício da docência, convocando-nos, constantemente, a colocarmos nossas formas de pensar e agir sob suspeita, dessubjetivando-subjetivando-nos. Questionar a identidade e a diferença como relações de 
poder significa problematizar os binarismos em torno dos quais elas se organizam, especialmente dois deles, branco/negro e homem/mulher.

Como instrumento de coleta de informação, adotamos as entrevistas semiestruturadas, para construir as narrativas sobre as trajetórias pessoais e profissionais das cinco professoras. A entrevista semiestruturada se organiza a partir de uma lista de questões para serem respondidas, como se fosse uma orientação e respeitando certa flexibilidade. As questões não precisam acompanhar a ordem prevista, podendo ser elaboradas novas perguntas no decorrer da entrevista. Assim, as narrativas caracterizam-se pela oportunidade de compartilhar memórias e histórias com mulheres negras que, ao se disporem a participar, ressignificaram suas lembranças e suas trajetórias, tornando-se sujeitos da sua história. Narrar é um processo individual que ocorre por meio das memórias, da seleção e avaliação do que querem recortar para compor suas trajetórias e suas representações de mundo (GOMES, 2018).

Como se trata de narrativas que estão imersas em identidades construídas em uma sociedade racista, podem ser consideradas como narrativas de resistência. São escritas de si que contribuem para superação de silenciamento e traumas vividos. Escritas que interrogam as condições e os efeitos das situações de opressão assujeitadoras.

Para Izaú Veras Gomes (2018, p. 5), as "narrativas de resistência ao se materializarem por meio da escrita, permitem uma nova tomada de consciência para seus narradores e a elaboração de uma visão contra hegemônica de mundo". Narrar as histórias de professoras negras é uma aposta por novas experiências, novos olhares, além de descortinar práticas racistas e machistas que ainda persistem no cotiando de nossas escolas, permitindo, ainda, novas possibilidades de pensar essas práticas e seus combates como relações de poder.

\section{Interseccionalidade raça e gênero}

Pensar as questões de gênero e raça nos remete às histórias e experiências de inúmeras mulheres negras, atuantes no combate às violências que lhe são impostas cotidianamente. Mais do que isso, nos conduz aos processos de objetivação/subjetivação que vão docilizando os corpos, tornando-os produtivos e úteis, situados em sua historicidade e constituindo indivíduos em sujeitos detentores de determinadas identidades que tomam como suas (FOUCAULT, 1988). São experiências que vão conferindo identidades a essas mulheres negras e a outras mulheres e homens que não participaram do programa de cotas. Os processos de objetivação/subjetivação dizem do trabalho de Foucault (1988) em torno da ontologia histórica dos sujeitos em relação com a verdade, com os jogos de poder e com a ética. A objetivação diz do modo como o sujeito pôde se tornar um objeto para o conhecimento. Trata-se de modos de objetivação que produzem subjetivações. A objetivação e a subjetivação não devem ser entendidas como uma após a outra, como sequências, mas, sim, como processos complementares e inseparáveis que se relacionam através dos jogos de verdade.

Nosso argumento é que há uma relação da constituição dos sujeitos com os saberes e os significados histórica e culturalmente constituídos. Para Foucault (1988), não há constituição de sujeito sem a relação saber/poder. Os sujeitos estão presos às relações de saber/poder. Em um relato sobre sua entrada na Universidade 
e as surpresas de encontrar um espaço sem a presença de negras, bell hooks ${ }^{3}$ (2013) defende que as intersecções de gênero e raça devem ser analisadas levando em consideração a história das mulheres negras. Ao trazer sua experiência, hooks (2013) nos faz refletir sobre a história do Movimento Negro no Brasil, seus desafios e conquistas. Um dos desafios que marcou o movimento foi a luta pela entrada nas Universidades, que passa pela reivindicação de outras epistemologias, outras formas de saber, de pesquisar e de construir outros sujeitos negros e não-negros, questionando a dissimetria entre a cultura oral e escrita e as relações de poder. Mas a entrada na Universidade não era suficiente, havia necessidade de permanência e de problematização sobre as formas de saber que eram valorizadas nesse espaço de saber/poder. A experiência de hooks, assim como as experiências das professoras, contribui para a problematização da história do Movimento Negro no Brasil a partir da interseccionalidade.

O termo interseccionalidade surge, no final dos anos 1970, junto aos debates empreendidos pelo Movimento Feminista Negro para designar a interdependência das relações de poder, de raça, sexo e classe. Segundo Gabriela Kyrillos (2020), o termo tem alcançado grande repercussão e tem contribuído para o avanço de pesquisas acadêmicas no Brasil. Para ela, foi “Kimberlé Grenshaw, jurista estadunidense, quem nomeou em 1989 e quem, posteriormente, desenvolveu algumas das mais importantes elaborações teóricas sobre esse conceito” (KYRILLOS, 2020, p. 1).

\begin{abstract}
A interseccionalidade pode ser entendida como uma ferramenta de análise que consegue dar conta de mais de uma forma de opressão simultânea. Com essa lente, os processos discriminatórios não são compreendidos isoladamente, nem se propõem uma mera adição de discriminações, mas sim, abraçase a complexidade dos cruzamentos dos processos discriminatórios e a partir daí se busca compreender as condições específicas que deles decorrem (KYRILLOS, 2020, p. 1).
\end{abstract}

Kimberlé Crenshaw é quem usa o termo interseccionalidade para definir os debates travados no Movimento Feminista Negro frente ao feminismo branco, de classe média, heteronormativo. (KYRILLOS, 2020). Novamente são as experiências de mulheres negras que são acionadas no processo de construção do conceito, a partir da observação de que as mulheres negras sofriam de dupla discriminação: a de gênero e a de raça. Nem o Movimento Feminista Branco dava conta de compreender essa intersecção, tampouco o Movimento Negro o compreendia. Dessa forma, as feministas negras perceberam que as discriminações deveriam ser analisadas em seu contexto, pois estas também se organizavam hierarquicamente.

Sirma Bilge (2018) define a interseccionalidade como categoria ampla de análise com o objetivo de compreender a amplitude das desigualdades frente às identidades. É um conceito que se refere a uma teoria transdisciplinar que busca compreender a complexidade das identidades e das desigualdades sociais. “Assim, os debates sobre a interseccionalidade também refletem lutas de poder, estruturas de oportunidade e disputas territoriais internas em disciplinas e campos específicos” (BILDE, 2018, p. 72). Com isso, a autora propõe olhar

\footnotetext{
${ }^{3}$ Gloria Jean Watkins, conhecida pelo pseudônimo de bell hooks, nasceu em Hopkinsville, em 25 de setembro de 1952. A autora de mais de 30 livros sobre raça, feminismo negro, afetividade e representação, entre outros temas, é ativista e teórica reconhecida em todo mundo. O nome "bell hooks" foi inspirado na sua bisavó materna, Bell Blair Hooks. A escolha da letra minúscula é justificada pelo interesse da autora em dar mais enfoque ao conteúdo desenvolvido em suas obras e menos a sua pessoa. Disponível em: https://almapreta.com/editorias/realidade/editora-lanca-livro-de-bell-hooks-sobre-racismo-em-saopaulo
} 
para a multiplicidade que compõe as realidades sociais, culturais, econômicas e políticas que organizam as relações de gênero nos seus atravessamentos de classe, raça, idade, orientação sexual.

Conquanto o uso do termo interseccionalidade como categoria de análise é recente, feministas negras, como Angela Davis (2016), questionavam há bastante tempo as opressões ignoradas por que passam as mulheres negras. Nesse sentido, a emancipação não eliminou a violência sobre as mulheres negras, que passou a ser exercida de outras formas, especialmente pelo sistema judiciário, que não as protegia de ataques sexuais por parte dos homens brancos. Pelo contrário. Se elas resistissem, "eram jogadas na prisão para serem ainda mais vitimizadas por um sistema que era um retorno a outra forma de escravidão” (DAVIS, 2016, p. 98). Com essas denúncias, Davis (2016) explicava o quanto o feminismo branco não atendia à demanda das mulheres negras e como o Movimento Negro não conseguia também abarcar suas reivindicações.

\section{História da lei de cotas e o caso da UEMG}

Escrever sobre a história da lei de cotas no Brasil passa, necessariamente, pela luta contra o racismo e pela defesa da educação como uma área primordial para a construção de uma sociedade menos desigual e desumana. Passa pela luta e organização do Movimento Negro. De acordo com Nilma Lino Gomes (2012), uma das características do Movimento Negro em relação à questão étnico-racial no Brasil é conquistar seu lugar de existência trazendo "o debate sobre o racismo para os espaços públicos e indagando as políticas públicas e seu compromisso com a superação das desigualdades raciais, este movimento social ressignifica e politiza a raça, dando-lhe um trato emancipatório e não inferiorizante” (GOMES, 2012, p. 233).

Nesse sentido, pensar a contribuição das mulheres no Movimento Feminista Negro e no interior do Movimento Negro significa dizer que a luta antirracista é uma forma de trazer à tona "as implicações do racismo e do sexismo que condenaram as mulheres negras a uma situação perversa e cruel de exclusão e marginalização sociais” (CARNEIRO, 2019, p. 287). Essa situação originou formas de resistências e de superação em que a educação e a luta pelo direito de entrar e permanecer na Universidade era parte desse projeto.

Segundo a Constituição de 1988, o direito à educação no Brasil, por lei, deveria ser assegurado pelo Estado em todos os seus níveis. No entanto, a realidade nos apresenta uma disparidade social que acrescenta barreiras para que certas camadas da população tenham acesso ao ensino superior nas universidades públicas brasileiras. A partir da III Conferência Mundial Contra o Racismo, Discriminação Racial, Xenofobia e Intolerância Correlata, realizada em Durban, África do Sul, em 2001, vivenciamos um aumento nas discussões a respeito das relações raciais no Brasil, principalmente sobre as diversas formas de discriminação vivenciadas pela população negra (BRASIL, 2013). Uma das consequências desse movimento foi a construção de políticas públicas desenvolvidas para atuarem contra o racismo no país, como destaca o texto do Plano Nacional de Implementação das Diretrizes Curriculares Nacionais para a Educação das Relações Étnico-Raciais e para o Ensino de História e Cultura Afro-Brasileira e Africana (2013):

O Parecer CNE/CP n 03/2004, aprovado em 10 de março de 2004 e homologado em 19 de maio de 2004 pelo Ministro da Educação, expressa que as políticas de ações afirmativas, no campo educacional, buscam garantir o direito de negros, negras e cidadãos brasileiros em geral ao acesso em todas as etapas e modalidades de ensino da Educação Básica, em ambiente escolar com infraestrutura adequada. Apregoa também que haja profissionais da educação qualificados para as demandas contemporâneas da sociedade brasileira e, em especial, que sejam capacitados para identificar e 
superar as manifestações do racismo como o preconceito racial e a discriminação racial. Dessa maneira haverá, na escola, uma nova relação entre os diferentes grupos étnico-raciais, que propicie efetiva mudança comportamental na busca de uma sociedade democrática e plural (BRASIL, 2013, p. 11).

A aposta era de que a introdução das temáticas de História da África e História e Cultura AfroBrasileira e Africana seria capaz de criar uma nova relação entre os diferentes grupos étnico-raciais, além de efetivar uma mudança nos comportamentos e relações entre as pessoas em favor de uma sociedade democrática e plural. Avançando no objetivo de possibilitar o acesso à educação pública para a população brasileira, o Ministério da Educação (MEC) ampliou e criou ações afirmativas voltadas para a promoção do acesso e permanência à educação superior. Entre elas, está o Programa Universidade para Todos (PROUNI ${ }^{4}$ ), ofertado aos estudantes egressos do ensino médio da rede pública ou da rede particular na categoria de bolsistas integrais, com renda per capita familiar máxima de três salários mínimos. O PROUNI, somado à expansão das universidades federais e ao Programa de Apoio a Planos de Reestruturação e Expansão das Universidades Federais $\left(\mathrm{REUNI}^{5}\right)$, expande significativamente o número de vagas no ensino superior. "Isso contribui para o cumprimento de uma das metas do Plano Nacional de Educação (PNE), que previa a oferta de educação superior até 2011 para, pelo menos, 30\% dos jovens de 18 a 24 anos” (BRASIL, 2004, p. 43).

A discussão nacional sobre cotas nas universidades públicas teve sua consolidação em 2012, quando 97 instituições públicas ${ }^{6}$ (entre universidades e institutos federais) de ensino superior brasileiras passaram a oferecer algum tipo de ação afirmativa a pobres, negros ou indígenas. Em agosto desse ano, a presidente Dilma Rousseff sancionou a Lei de Cotas Sociais, $n^{\circ}$. 12.711, a qual determinou que, até agosto de 2016, todas as instituições de ensino federais deveriam reservar, no mínimo, 50\% das vagas para estudantes que cursaram o ensino médio em escolas públicas, sendo que metade dessas vagas deveriam ser reservadas para estudantes cujas famílias têm renda de até um salário mínimo e meio. A outra metade deveria ser destinada para autodeclarados negros e negras, pardos e pardas e índios e índias. Sintetizando, 50\% das vagas seriam divididas entre estudantes de escolas públicas, pobres, negros, pardos ou índios e 50\% seriam destinadas à ampla concorrência (BRASIL, 2012).

Não é raro encontrarmos argumentos que servem para afirmar que o acesso ao ensino superior não soluciona o problema da depreciação histórica sofrida pela população afrodescendente no Brasil. No entanto, para Rita Segato (2006), a não discussão do tema nos mais variados ambientes e instituições corroboram para que o racismo não saia do cenário nacional. Para a autora, a forma de entender e de conhecer é uma das organizadoras da discriminação e exclusão por motivos raciais, sendo sutil e naturalizada (SEGATO, 2006).

Segundo Luíza Barros Rozas (2009), o Brasil é o segundo país com maior população negra no mundo, perdendo apenas para a Nigéria. No entanto, esses números não refletem a realidade nas Universidades. “A cor do campus, portanto, é diferente da cor da sociedade. Esse quadro de desigualdade racial é ainda mais dramático

\footnotetext{
${ }^{4}$ O PROUNI é um programa que tem como objetivo o acesso de estudantes de baixa renda às universidades particulares, sendo necessário terem cursado todo ensino médio em escolas públicas ou terem sido bolsistas em escolas particulares. Criado em 2004, durante o governo Lula, pela lei $\mathrm{n}^{0}$ 11.096, foi implementado a partir de 2005, sendo responsável por um importante trabalho de inclusão social.

${ }^{5}$ REUNI foi um programa criado no início do segundo mandato do governo Lula, pelo decreto presidencial $\mathrm{n}^{\circ}$ 6.096, com o objetivo de dar às instituições condições de expandir o acesso e garantir a permanência no ensino superior.

${ }^{6}$ Segundo site do MEC http://portal.mec.gov.br/cotas/perguntas-frequentes.html. Acesso em: 20 abr. 2020.
} 
se verificarmos que essa pequena parcela de negros está concentrada em cursos de baixa demanda” (ROZAS, 2009, p. 10). O resultado desse quadro é a manutenção de uma história de exclusão que remonta a nosso passado escravocrata e nos exige posicionamentos políticos pelo desmonte dessa situação. "Portanto, sem acesso à educação de qualidade e ao mercado de trabalho, os negros são deixados à margem da convivência social e da experiência democrática na comunidade política, restando-lhes ínfimas oportunidades de ascensão social no Brasil” (ROZAS, 2009, p. 10).

Embora a escolaridade tenha aumentado sucessivamente ao longo do século XX, para todos os brasileiros, a diferença assinalada manteve-se estável, a educação de negros e negras sempre ficou aquém da educação da população branca. A ação afirmativa do tipo cotas para ingresso ao ensino superior brasileiro é importante, pois, como descreve Tayson Ribeiro Teles (2015), consolida a dignidade da pessoa humana, valor constitucional supremo e fundamento da República Federativa do Brasil, além de não violar um dos princípios da constituição, o da igualdade. (TELES, 2015).

Na UEMG, a lei de cotas $n^{\circ}$. 12.711 foi sancionada em 29 de agosto de 2012. Apesar disso, as cotas já eram uma realidade na Universidade do Estado de Minas Gerais (UEMG) desde o início no ano de 2005. Trata-se de uma exigência da lei estadual $n^{0}$ 15.259, de julho de 2004, que obrigava as instituições do Estado a separarem, em cada curso, 20\% das vagas para afrodescendentes, desde que carentes; mais 20\% para candidatos que estudaram em escolas públicas; e outros 5\% para deficientes e indígenas. Na Universidade do Estado de Minas Gerais, a entrada ocorre pelo vestibular e pelo Sistema de Seleção Unificada (Sisu $)$, que é o sistema informatizado gerenciado pelo Ministério da Educação (MEC) no qual instituições públicas de ensino superior oferecem vagas para candidatos participantes do Exame Nacional de Ensino Médio (Enem).

A polêmica em torno das cotas não é recente e não está limitada aos aspirantes à universidade. Desde sua implementação, vêm sendo elaboradas diversas análises acadêmicas, e até mesmo judiciais, contrárias a essa alternativa, aqui avaliada como possível, necessária e equitativa, quando comparada aos anos de exclusão das mulheres e homens negros no nosso país. A atuação de mulheres negras ex-cotistas na sala de aula pode nos apresentar possibilidades de avanço na discussão contra a discriminação racial. Autoras como Petronilha Beatriz Gonçalves e Silva (1997) e Nilma Lino Gomes (2003) vêm discutindo a importância da formação docente na desconstrução dos preconceitos, reconhecendo o papel da escola e da educação como instâncias problematizadoras comprometidas com a mudança social. Por isso, voltar os olhos e a atenção para atuação em sala de aula de mulheres negras professoras ex-cotistas é buscar estabelecer um encontro entre história, experiência, formação e atuação docente.

\section{Narrativas das professoras negras: de cotistas a profissionais da educação}

A chegada ao magistério, para a mulher negra, pode ser considerada o rompimento com um processo de exclusão que lhe é imposto historicamente, culminando com várias rupturas. Foucault (1988), quando afirma que o sujeito é um efeito das relações de poder e das relações de saber, convida-nos a pensar nossos processos de subjetivação, já que, mesmo sendo sujeitados, os indivíduos possuem um campo de possibilidade para várias

\footnotetext{
${ }^{7}$ Criado pelo governo Lula em 2009, o Sisu é uma plataforma digital desenvolvida pelo MEC e utilizada pelos estudantes que realizaram o Enem para se inscreverem nas universidades que aderiram ao sistema, sendo hoje uma das principais formas de acesso à universidade.
} 
condutas e diversos comportamentos. Nessa perspectiva, a resistência e a luta da população negra são para ressignificar sua história e ocupar espaços de decisões e políticas públicas que insiram a população negra nas instituições e espaços que sempre lhe foram negados.

Uma primeira ruptura com essa história que atinge a população negra é vencer o desafio de continuar os estudos para além do ensino médio, além do rompimento com a trajetória de suas mães e familiares de atuar em uma profissão que lhes permita outros espaços de trabalho que não o de uma casa (sua ou a de uma outra família), como domésticas. Todas as cinco mulheres negras foram as primeiras de suas famílias a ingressar numa universidade pública, rompendo com um ciclo que se renovava entre mulheres em atividade doméstica. Por último, representa a perspectiva de uma conquista econômica advinda do processo de ascensão da população negra, ou seja, envolve a questão racial atravessada pelas questões de gênero. Como suas histórias de vida são marcantes nas suas posturas nas escolas, as memórias do que viveram estão presentes no cotidiano escolar como forma de não repetirem, com as alunas, o que vivenciaram. Ao questionarmos as professoras sobre a relação entre sua trajetória escolar, sobre terem sido cotistas, seu processo de formação e sua atuação prática, todas afirmaram que trabalham as temáticas de gênero e raça na escola:

Claudia $^{8}$ : Vejo resistência de colegas ao querer trabalhar temas raciais com os alunos da Educação Infantil, mas eu sei que é necessário, pois, quando estou com os alunos do Fundamental, vejo que eles já têm práticas racistas. Eu busco sempre trazer as temáticas raciais para dentro da sala de aula, mesmo nas pequenas coisas. Em uma das escolas que eu trabalho, eu sou a única professora negra e vejo como é importante ter essa representatividade para os alunos que são negros. Assim que me formei, eu comecei a fazer concursos e participar de designação, pois eu não queria trabalhar em escola particular, por não gostar das metodologias adotadas. Toda vez que eu chegava às designações, as pessoas achavam que estava lá para concorrer às vagas de faxineira, cantineira. Quando eu consegui uma vaga de supervisão escolar, foi complicado, pois eu era negra e jovem e as outras professoras todas mais velhas. Eu tive que ouvir de um professor em uma reunião que eu deveria estar procurando é sambar e não ser supervisora.

Carolina: Minha trajetória de vida reflete muito na minha atuação hoje, eu sempre penso que não vou repetir com o outro algo de negativo que fizeram comigo. Tudo o que eu passei me trouxe um aprendizado, convivi com muitas pessoas, adquiri valores, respeito, igualdade e equidade. Por exemplo, busco esclarecer para os meus alunos que as cotas são uma busca pela equidade. Como trabalho também numa escola particular, eu vejo o quanto o ensino é mais avançado e que não dá para colocar os alunos destas em condição de igualdade com os oriundos de escola pública. Eu sei que minha função é trabalhar para alcançar a igualdade, mas enquanto não está, tem que ter estas ações.

Marielle: A minha vida me fez passar por situações que não vou reproduzir nas escolas. As práticas que desenvolvo são diversas, relacionadas ao respeito, mas também sobre a valorização dessas crianças. Se tem alguma atitude de preconceito, eu chamo pra conversar, eu dou exemplos, fazemos atividades em que todos se reconheçam como iguais e com diferenças. As crianças são fáceis de se aceitarem é depois que crescem que as coisas mudam.

Lélia: De manhã eu trabalho na Educação Básica com supervisão, eu procuro colocar as discussões da temática negra para as professoras trabalharem. No cargo da tarde eu também busco colocar as questões raciais em pauta. A minha pesquisa do mestrado é sobre a questão do cabelo e corpo negro. Eu tenho uma filha e ela passou pela questão da identificação racial aos 3 anos. Eu fiquei chocada dos coleguinhas, naquela idade, terem esse tipo de atitude e também me assustei, pois achei que estava orientando ela bem, que ela ia conseguir passar por esse tipo de situação sem se abalar, mas ela recebeu com um impacto muito grande.

As vivências como mulheres negras apareceram em todas as falas como marcas de constituição e como determinantes nas formas de elas olharem para o mundo e para suas funções como professoras negras. Como nos

\footnotetext{
${ }^{8}$ Todos os nomes das mulheres negras participantes são fictícios, mantendo, assim, o anonimato.
} 
lembra Joan Scott (2019), o gênero e podemos ampliar para a raça são marcadores sociais. Defendendo o gênero como uma categoria útil de análise histórica, Scott (2019) argumenta que não basta incluir as mulheres nos processos de escolarização e tampouco na história, há necessidade de as mulheres participarem da escrita da história, tanto nas suas próprias quanto nas histórias da humanidade. As mulheres, quando tomam a palavra, introduzem novas temáticas, novas avaliações críticas do mundo, como aparece nas falas das cinco professoras. Cláudia admite: "Vejo resistência de colegas ao querer trabalhar temas raciais”, de maneira que sua presença e história de vida propõem novas temáticas capazes de acionar resistências. As resistências, na perspectiva foucaultiana, são forças das relações de poder, são partes do poder e, como forças, devem ser tão inventivas quanto o poder (FOUCAULT, 1988). As resistências que Claudia enfrenta, fornecem um lugar para ela na escola, o lugar de mulher negra que discute questões raciais nos seus atravessamentos de gênero. Modificar o seu lugar na escola e na história modifica o lugar das pessoas que estão ao seu redor.

Carolina, por sua vez, toma sua história de vida para avaliar e projetar sua ação como professora: “Minha trajetória de vida reflete muito na minha atuação hoje, eu sempre penso que não vou repetir com o outro algo de negativo que fizeram comigo”. Elizabeth Ellsworth (2001), no seu trabalho com cursos de formação, nos convida a pensar o exercício da docência nas salas de aula, defendendo que todo trabalho está organizado a partir das respostas que somos capazes de construir para duas questões: quem eu penso que o meu aluno e minha aluna são? Quem eu quero que eles e elas sejam? Responder a essas duas questões é uma aposta na mudança social, na transformação via educação e via o trabalho e ação dos professores e professoras. No caso aqui discutido, que é ação de professoras negras na educação, podemos pensar que isso se amplia, tentando construir a escola como espaço de acolhimento, como “espaço seguro”, como define Patrícia Hill Collins (2019).

Em um artigo em que se dedica a discutir o “poder da autodefinição”, a feminista negra Patrícia Hill Collins (2019, p. 271) afirma que "há muito tempo existem atos de resistência, tanto organizados quanto anônimos”. Mesmo que individuais, esses atos de resistência também trazem à tona uma consciência coletiva e característica daquelas pessoas que conhecem a opressão de gênero e racial desde muito cedo, de maneira que essas pessoas não são vítimas, mas sobreviventes, como classifica a autora. Patrícia Hill Collins (2019) está se referindo aos corpos de mulheres afro-americanas para colocar sob suspeita as hegemonias que nos constituem, assim como o poder da fala, da autodefinição e da escrita de si como formas de luta dessas mulheres. "Suas ideias e ações não só sugerem que existem um ponto de vista autodefinido e de grupo de mulheres negras, mas que sua presença foi essencial para a sobrevivência das mulheres negras norte-americanas” (COLLINS, 2019, p. 273).

Embora a autora esteja se referindo a mulheres negras norte-americanas, podemos traçar um diálogo com as mulheres negras brasileiras na constituição de suas redes de solidariedade. Redes que são construídas na identificação dos “espaços seguros”, que, para Patrícia Hill Collins (2019), não são somente espaços de segurança em que se pode falar com liberdade, mas espaços que também "formam os lugares primordiais para resistir à objetificação como o outro” (COLLINS, 2019, p. 276). A autora reconhece e nomeia três espaços seguros para as mulheres negras norte-americanas: a amizade/interações familiares, a música e a escrita. As professoras cotistas parecem reconhecer, no seu trabalho com as demais crianças negras, esse espaço seguro construído pela rede de pertencimento de raça e de gênero. 
A fala de Claudia apresenta, já no início, a difícil realidade de ser negra nesse país. "Você deveria estar procurando sambar e não ser supervisora" é uma das agressões racistas mais comuns para as mulheres negras. Trazer essa lembrança numa pesquisa que discute formação dos sujeitos nos indica que sua ação é pela não reprodução dessa história com outras mulheres negras. A erotização e a discriminação do corpo negro ficam explícitas em uma frase dita dentro de uma escola, lugar de formação de sujeitos, por um professor com curso superior. Importante ressaltar que não há aqui nenhum discurso contra o samba, a cultura ou as mulheres negras que gostam e trabalham com a dança. Não queremos também apresentar uma definição de que só existe objetificação dos corpos da mulher negra, pois sabemos que todas as mulheres são objetificadas culturalmente, negras, brancas, cis e trans etc. No entanto, o que marca é que o professor diz essa frase também com o objetivo de menosprezar a formação e a dedicação de Claudia ao trabalho.

De acordo com Claudia Lemos Pacheco (2013), o estereótipo da mulata, que ainda sobrevive no imaginário social da sociedade brasileira, recai violentamente sobre nossos corpos e nossos afetos. Dessa forma, nossa cor representa sexualidade. Nessa perspectiva, muitas mulheres negras sequer conhecem o amor. O racismo perpassa tanto o nosso corpo concreto quanto a fantasia construída sobre nossos corpos, já que "é sobre o ato de amar e ser amada que se alojam as hierarquias sociais prescritas e as representações elaboradas a respeito do corpo da negra/mestiça, estruturando suas escolhas e sua afetividade” (PACHECO, 2013, p. 28).

Para além do ato racista do colega de trabalho, Claudia cita a importância de sua representatividade enquanto única mulher negra no espaço escolar: "em uma das escolas que eu trabalho, eu sou a única professora negra e vejo como é importante ter essa representatividade para os alunos que são negros”. A não presença de pessoas negras nos espaços de poder nas escolas faz com que tanto brancos quanto negros aprendam a naturalizar esses papéis. Assim, estudantes negros e negras não se veem como possíveis candidatos a ocupar esses espaços, tornando a escola um lugar distante da realidade da maioria dessas crianças. De acordo com Marzo Santos e Vicente Neto (2011), a presença de professoras negras no ambiente escolar é um estímulo a estudantes negros e negras para se reconhecerem e perceberem a escola como seu lugar:

\begin{abstract}
A presença efetiva do negro na escola é fundamental, pois traz à tona muitos aspectos ocultos da nossa história e permite que os sujeitos possam se enxergar nos livros, nos fatos e nos ídolos de forma digna. Os sujeitos identificados como representantes de prestígio da raça/etnia no contexto estudado possibilitam que alguns estudantes negros reconheçam seu pertencimento étnico-racial e, dessa forma, possam assumir uma postura de liderança e de exemplo em suas relações. Na escola, o negro está majoritariamente representado no(a) servente, no(a) guarda, no(a) cozinheiro(a), posições que não desfrutam de um reconhecimento valorizado entre os estudantes. A discriminação "mais sofisticada", presente nos livros didáticos, no currículo escolar, nos meios de comunicação, entre outros, é mais difícil de ser percebida, mas ao longo do tempo esse tipo de discriminação causa uma assimilação dos estereótipos negativos veiculados ao negro. É mais fácil perceber a discriminação em situações concretas, nas quais a ação do racismo é imediata (SANTOS; NETO, 2011, p. 531).
\end{abstract}

A citação acima nos apresenta dois tipos de discriminação e racismo em torno dos estereótipos dos negros: um mais sutil, presente nos currículos e livros didáticos, e outro mais concreto, que se materializa nas relações entre as pessoas. Esses dois tipos de situação aparecem nas falas das professoras, como na de Elza, que destaca a necessidade do cuidado para não reproduzir experiências como as que vivenciou, ressaltando a importância de trazer ao cotidiano das estudantes um conhecimento positivo sobre a trajetória dos povos negros: 
"busco trabalhar as questões da negritude em sala constantemente, mas de uma forma que os leve a enxergarem como o povo negro é guerreiro e sempre os incentivando a questionar". Com isso, parece atacar tanto a ausência de personagens negros na História e no Currículo oficial das escolas como no enfrentamento das discriminações concretas investindo na autoestima de seus alunos e suas alunas negras. A sua experiência organiza sua ação para que outras meninas não vivenciem a repetição dessas discriminações.

Marielle cita a facilidade das crianças em lidar com as diferenças, ressaltando que é quando crescem que as questões se acirram. Destaca, ainda, que, quando há necessidade, ela chama as crianças para conversar sobre o tema, além de desenvolver atividades nessa perspectiva. Lélia, apresentando argumentos fortes para sua atuação frente a uma educação antirracista, salienta o trabalho que faz como supervisora escolar desenvolvendo, durante todo o ano, atividades relacionadas à temática afrodescendente. Estar na posição de supervisora pedagógica na escola the permite imprimir, para além de sua sala de aula, a temática racial, possibilitando toda a escola atuar com o tema. Esse olhar é essencial para a difusão dessas práticas no ambiente escolar, mas novamente fica a impressão de quem pensa essas temáticas são os/as profissionais que possuem relação direta com o tema.

Ter presenciado sua filha, aos três anos, desejar não ser negra, após sofrer racismo na Educação Infantil, faz Lélia atuar, desde o berçário, com a valorização da estética negra. Lélia se choca com a atitude de discriminação de crianças tão pequenas. Cavalleiro (2010) assevera que as crianças vão aprendendo muito cedo sobre os processos de categorização à sua volta e, da mesma forma, vão perceber as diferenças na cor de pele, cabelo, roupas, aprendendo, assim, também, a classificar. Todavia, é a sociedade que determina quanta atenção deve ser dada para essas variações "e dá à criança a noção da identidade étnica que é limitada pela consistência das atitudes físicas e do comportamento; é a sociedade que ensina como aquela identidade deve ser valorizada” (CAVALLEIRO, 2010, p. 289). Nesse sentido, as práticas apresentadas por essas professoras são essenciais para a atuação numa perspectiva antirracista.

Fica exposta, nas memórias apresentadas pelas professoras, a importância da escola em sua constituição como sujeitos e construção de identidades. Mas como estas analisam o papel da escola na vida de seus estudantes?

Claudia: O papel da escola é fundamental, pois o professor já chega à escola com a carga de aluno. Eu olho minhas alunas negras e vejo que elas passam, ainda hoje, tudo o que eu passei, apesar de hoje elas terem mais coragem para enfrentar as situações do que eu tinha na minha época. Eu trabalho numa escola em área de periferia, então, muitas vezes, a escola é o único lugar onde as crianças podem se divertir, comer, aprender, então tento proporcionar boas vivências a elas.

Carolina: Eu vejo a escola e os professores como formadores, aquilo que eu faço tem influência. Por exemplo, eu sempre usei trança no meu cabelo, e minhas alunas, às vezes, combinam um dia de irem todas de tranças, eu vejo que elas estão se reconhecendo em mim.

Elza: É fundamental, foi na escola que eu aprendi a me reconhecer, a reconhecer minha família, levo para minha família essa valorização da negritude, incentivo minhas irmãs a assumirem o cabelo negro, deixarem de se agredir por causa de padrões estéticos. A escola, além de formar quem está ali, ela leva conhecimento para fora, para casa, para uma roda de amigos. A falta de conhecimento nos oprime e não permite que tenhamos argumentos para nos defender. O conhecimento traz liberdade. Minha filha está na PUC com bolsa do Prouni, sempre estudou em escola pública e agora está na graduação. Também gosta da temática negra/afrodescendente. O papel da educação é abrir a mente das pessoas, abrir a cabeça, mostrar novos pontos de vista. O meu grupo do projeto de cotista da época era o pilar dos debates sobre o tema, alguns professores tinham muita resistência às cotas, uma 
professora até me desafiou a convencê-la de que as cotas eram boas, ela não concordava, pois dizia desfavorecer outros alunos que tinham a mesma questão social. Nós começamos a argumentar, citamos pesquisas que mostram que nas piores escolas públicas encontra-se o maior número de negros. Teve uma colega minha que me questionou como eu tinha conseguido entrar, ela não entendia como eu consegui passar no vestibular, achava que eu não era capaz, expliquei que fiz a prova assim como ela.

Marielle: É muito importante, muda a mentalidade, abre a visão, faz as pessoas refletirem, pesquisar, ensina os estudantes a pesquisar ao invés de copiar e tirar as próprias conclusões. Mostra que mesmo a pessoa não concordando, ela tem que entender o que está por trás dos fatos. Vejo que meu papel é também fazer os professores refletirem antes de julgar ou sair reproduzindo alguma notícia que recebem.

Em todos os relatos, o saber da experiência se mistura ao saber constituído durante o processo de formação, como discutido por Tardif (2014). O autor destaca que o saber é sempre o saber de alguém que trabalha alguma coisa no intuito de realizar um objetivo qualquer, o saber não é algo que flutua no espaço. Assim, pensar uma forma de ensino que promova o respeito às diversidades passa por repensar os saberes que constituem nossos currículos e nossas práticas. O saber não pode ser limitado, único, é criando novas possibilidades que construiremos uma escola com e para a diversidade. Ainda de acordo com Tardif (2014, p. 36), o "saber docente é um saber plural, formado pela organização mais ou menos coerente de saberes oriundos da formação profissional, de saberes disciplinares, curriculares e experienciais”. E, de acordo com o autor, não há saber maior ou melhor, existem saberes e experiências diferentes que, juntos, podem permitir à escola e, especialmente, aos/às estudantes, experiências de transformação.

Antônio Nóvoa (1995) também dá destaque aos saberes da experiência: “a formação não se constrói por acumulação de cursos, de conhecimentos ou de técnicas, mas sim através de um trabalho de reflexividade crítica sobre as práticas e de (re)construção permanente de uma identidade pessoal” (NÓVOA, 1995, p. 21). Nessa perspectiva, conhecer e aprender com os saberes da experiência, tais como as memórias e relatos de nossas professoras, pode contribuir para repensar e criar novas estratégias de investimento na escola e seus integrantes.

Nessa perspectiva, ainda de acordo com Tardif (2014), os saberes docentes e sua relação com o cotidiano propõem uma revisão da compreensão do cotidiano e da prática pedagógica do professor, que é tomado como mobilizador de saberes profissionais. Considera-se, assim, que o professor, em sua trajetória, constrói e reconstrói seus conhecimentos conforme a necessidade de sua utilização, suas experiências, seus percursos formativos e profissionais, como fica explícito nos relatos das memórias e práticas de nossas professoras. Claudia faz uma séria denúncia das práticas racistas nas escolas, no ano de 2019, 16 anos após a lei $n^{\circ}$ 10.639/039 ter sido implementada. Claudia também destaca a experiência de já ter sido estudante e ter vivenciado as situações pelas quais as crianças passam a vivenciar nesse espaço e a importância de sua prática para que as experiências de suas alunas sejam melhores. Carolina cita a importância da representatividade e do papel do/a educador/a como formador/a e influenciador/a desses/as estudantes.

Elza destaca o papel da escola como formadora de identidades e sujeitos e de como as experiências vividas na instituição se expandem para os núcleos familiares desses/as estudantes, contribuindo para uma

\footnotetext{
${ }^{9}$ A Lei $n^{0}$ 10.639, de janeiro de 2003, altera a Lei $n^{0}$ 9.394, de 20 de dezembro de 1996, que estabelece as diretrizes e bases da educação nacional, para incluir no currículo oficial da rede de ensino a obrigatoriedade da temática "História e Cultura Afro-Brasileira".
} 
formação formal na escola e informal, quando esses/as estudantes levam para casa seus conhecimentos. Elza destaca, ainda, a importância da política de cotas para dar continuidade à formação na sua família e como o conhecimento pode significar novas possibilidades. Para ela, “o papel da educação é abrir a mente das pessoas, abrir a cabeça, mostrar novos pontos de vista. O meu grupo do projeto de cotista da época era o pilar dos debates sobre o tema, alguns professores tinham muita resistência às cotas, uma professora até me desafiou a convencê-la de que as cotas eram boas”.

Todas as professoras citaram, em algum momento, a manifestação de seus/suas professores/as na graduação questionando a política de cotas. Destacam a importância da união do grupo de cotistas para enfrentar o racismo e citam alguns exemplos de como eram as responsáveis pelo debate racial na instituição. Podemos perceber, dessa forma, a importância da política de cotas e de como a presença negra, nos espaços antes ocupados somente pela branquitude, incomoda, faz pensar e reorganiza a estrutura da universidade.

Para Petronilha Baetriz Gonçalves e Silva (2003), ao mexer na estrutura das desigualdades, buscando construir um processo de equidade entre negros, índios, brancos e amarelos nas universidades, ressignifica-se a maneira de pensar, de produzir conhecimento e da ideia de universidade no Brasil. As políticas de inclusão socioeconômicas sozinhas não combatem o racismo. No entanto, trocar cotas raciais por econômicas, como argumentavam os/as professores/as das nossas entrevistadas durante a graduação, é um artifício para negar a discriminação racial no Brasil. Seria como dizer que basta dar a mesma condição econômica a toda população que não mais haverá discriminação racial. A exclusão dos candidatos de baixa renda é uma injustiça que deve ser reparada com as políticas de inclusão social. Mas isso não acaba com o racismo institucionalizado e não resgata a dívida histórica que o país tem com seus cidadãos pretos, pardos e índios, nem pode servir de argumento para questionar as cotas raciais. Ainda de acordo com Petronilha B. Gonçalves e Silva (2003):

\begin{abstract}
As instituições de ensino superior que reconhecem a diversidade social e econômica da população brasileira, sua pluralidade cultural e racial e as avaliam como injustas, ao reservar vagas para negros, projetam ser socialmente justas, e para tanto têm de ampliar seu campo de visão e de produção do conhecimento. Uma instituição, que se disponha a implantar plano de ações afirmativas para a população negra, não pode encará-lo como "proteção a desvalidos", segundo pretendem alguns. É preciso que um plano com tais metas incentive a compreensão dos valores da diversidade social, cultural, racial e, nestes valores, busque apoio para orientar suas ações educativa, de formação de profissionais e de responsável pelo avanço das ciências. Sem dúvida, a universidade, ao prever e executar medidas visando à inclusão de grupos até então deixados à margem, inclui-se na sociedade, passa a dela fazer parte e assume compromisso com ela, já que deixa de atender unicamente aos interesses de um único segmento até então privilegiado (SILVA, 2003, p. 48).
\end{abstract}

Ainda sobre o papel da escola, Marielle analisa que esta deve formar, informar e dar aos/às estudantes a opção de escolhas, mas destaca que é também espaço para debater com os/as colegas de profissão a divulgação indevida de inverdades. Já para Lélia, escola e família são responsáveis pela construção identitária da criança e, nesse sentido, há necessidade do cuidado com a profissão e suas consequências na vida dessas estudantes.

As representações sociais são importantes na constituição das diferenças, orientando, muitas vezes, ações e formas de agir e, dependendo de quem temos como referência, iremos silenciar ou destacar as diferenças como parte de nossa formação. Silenciando, contribuímos para a autorrejeição de nossos/as educandos/as e para a valorização da cultura dominante. O cuidado e a responsabilidade das professoras ouvidas neste estudo com a formação de seus/suas educandos/as numa perspectiva antirracista endossam a importância da política de cotas e 
de uma formação de professores as quais estejam atentas às demandas da sociedade, promovendo uma educação numa perspectiva plural e inclusiva.

Cavalleiro (2010) aponta a necessidade de formação de educadores na perspectiva que apresentam nossas entrevistadas, pois, na educação, o quadro permanece desvantajoso para o segmento negro da população. Ainda de acordo com a autora, nas escolas brasileiras, o racismo aflora de inúmeras formas, explícitas ou não:

O silêncio dos professores perante as situações de discriminação impostas pelos próprios livros escolares acaba por vitimar os estudantes negros. Esse ritual pedagógico, que ignora as relações étnicas estabelecidas no espaço escolar, pode estar comprometendo o desempenho e o desenvolvimento da personalidade de crianças e de adolescentes negros, bem como estar contribuindo para a formação de crianças e de adolescentes brancos com um sentimento de superioridade (CAVALLEIRO, 2010, p. 512).

Como pudemos perceber, todas consideram a política de cotas importante para o avanço da luta contra o racismo em nossa sociedade. Defendem, argumentam e demonstram, a partir de suas experiências, a necessidade dessas políticas. As práticas das professoras buscam, cada uma a sua forma, enfrentar o racismo, sexismo e demais violências, tão presentes em nossa sociedade. Não é fácil enfrentar o racismo, mesmo tendo uma lei que exija o desenvolvimento de ações que valorizem e debatam a participação dos povos negros e indígenas nas escolas. É recorrente, nos relatos das professoras, que essas práticas ainda são escassas e, quando existem, são levadas pelas pessoas que já vivenciaram o racismo em sua trajetória.

\section{Considerações finais}

Ao longo do artigo, mostramos o vínculo que se estabeleceu entre as experiências vividas por essas mulheres negras e suas ações como professoras de outras crianças negras e brancas. Vínculos de experiência, tanto no que se refere ao pertencimento ao gênero feminino quanto à raça negra, demonstrando a impossibilidade de separar esses dois organizadores sociais. Somos sujeitos de experiências, o que significa tomar a experiência como sendo resultado de uma certa tensão entre saber, poder e subjetivação. Para o autor, a experiência só é possível no processo de dessubjetivação/subjetivação. Fazer parte da primeira turma de cotistas da UEMG marcou a história da instituição e dessas mulheres. Depois de participarem dessa formação, não foram mais as mesmas, se dessubjetivaram e investem nesse processo de dessubjetivação/subjetivação nos seus alunos e alunas, apostando no poder da educação como espaço de ruptura e descontinuidade histórica, capaz de modificar os sujeitos e a sociedade. Elas são resultado dessa aposta e mantêm viva essa esperança de transformação de si e do outro em seus processos educativos.

As falas das cinco professoras nos mostram que a experiência se revela pelo valor que as questões nos apoderam e nos constituem. Não é fácil falar de si, descrever uma trajetória, de maneira que sempre corremos o risco de demorar em questões desnecessárias para o/a leitor/a e desandar nessa leitura do eu. Como o labirinto da memória não nos revela a forma concreta da realidade vivida, o que somos capazes de lembrar é sempre um relato ponderado sob o olhar daquele que lembra, no e a partir das questões do presente, fragmentos de sua história com o outro e consigo. Elas foram atribuindo sentido às suas memórias e selecionando o que consideravam importante a partir do olhar como professoras negras ex-cotistas, de maneira que essas três identidades se mostraram inseparáveis nos relatos. Mas, se somos sujeitos de experiências, também somos assujeitadas aos discursos, somos construções discursivas. Quando nascemos, já viemos num mundo organizado 
discursivamente, o que significa que somos muito mais produtos de discursos do que produtoras deles. No entanto, isso não significa ficarmos atrelados/as a esses discursos que nos produzem, mas, ao contrário disso, somos convocados/as pela problematização, a rompermos com eles e a nos constituirmos de outras maneiras, a pensarmos outras formas de ser e estar no mundo.

Mulheres negras que, ao ingressarem na Universidade do Estado de Minas Gerais pelo processo de cotas, transformaram-se em mulheres negras cotistas, adquiriram nova identidade que as marcou como as primeiras cotistas negras da UEMG. Um processo que diz de uma historicidade do sujeito, que se torna nosso tema de investigação na relação com o presente. Assim como Foucault, nossa análise nasceu e não se distanciou de uma problemática do presente, mas que nos exige um constante retorno ao passado, um passado histórico próximo ou mesmo distante. Não é possível tomar a trajetória dessas mulheres negras cotistas e professoras sem um olhar para o passado de luta do Movimento Negro organizado e tampouco o passado mais longevo que marca a história das mulheres negras de um país com um passado escravocrata, racista e preconceituoso. A problemática de constituição dos sujeitos nos ensina que o sujeito não é algo dado nem essência, mas, sim, resultado de um processo complexo de constituição, que envolve a relação com os saberes, com os discursos e com as relações de poder.

\section{Referências}

BILGE, S. Interseccionalidade desfeita: salvando a interseccionalidade dos estudos feministas sobre interseccionalidade. Revista Feminismos. Salvador: NEIM-UFBA, vol.8, n.3, p. 67-82, set. - dez. 2018.

BRASIL. Os desafios do Plano Nacional de Educação / Instituto Nacional de Estudos e Pesquisas Educacionais Anísio Teixeira. - Brasília: O Instituto, 2004. 191p.

BRASIL. Lei n 12.711, de 29 de agosto de 2012. Dispõe sobre o ingresso nas universidades federais e nas instituições federais de ensino técnico de nível médio e dá outras providências. Disponível em <http://www.planalto.gov.br/ccivil_03/_Ato2011- 2014/2012/Lei/L12711.htm> Acesso em: 16 out. 2019.

BRASIL. Plano Nacional de Implementação das Diretrizes Curriculares Nacionais para Educação das Relações Étnico-raciais e para o Ensino de História e Cultura. [2a Edição] - Brasília: MEC, 2013 - 103 p. + 1 CD-ROM.

CARNEIRO, S. Escritos de uma vida. São Paulo: Pólen Livros, 2019.

CAVALLEIRO, E. S. Do silêncio do lar ao silêncio escolar: racismo, preconceito e discriminação na educação infantil. São Paulo: Contexto, 2010.

COLLINS, P. H. Pensamento feminista negro: o poder da autodefinição. In: HOLLANDA, H. B. (org.). Pensamento feminista: conceitos fundamentais. Rio de Janeiro: Bazar do Tempo, 2019.

DAVIS, A. Mulheres, raça e classe. 1. ed. São Paulo: Boitempo, 2016.

ELLSWORTH, E. Modos de endereçamento: uma coisa de cinema, uma coisa de educação também. In: SILVA, T. T. Nunca fomos humanos - nos rastros do sujeito. Belo Horizonte: Autêntica, 2001.

FOUCAULT, M. História da sexualidade I: a vontade de saber. Rio de Janeiro: Graal, 1988.

GOMES, I. V. Narrativas estudantis negras: Sentidos da Educação Física escolar para a educação étnico-racial. In: XI COPENE. (Re) existência intelectual negra e ancestral. 18 anos de resistência. 2018. Uberlândia. MG. 
GOMES, N. L. A mulher negra que vi de perto - o processo de construção da identidade racial de professoras negras. 2. ed. Belo Horizonte: Mazza Edições, 2003. 128p.

GOMES, N. L. Movimento Negro e educação: ressignificando e politizando uma raça. Revista Educ. Soc., Campinas, v. 33, n. 120, p. 727-744, setembro de 2012.

hooks, b. Ensinando a transgredir: a educação como prática da liberdade. São Paulo: Editora WMF. Martins Fontes, 2013.

KYRILLOS, G. M. Uma Análise Crítica sobre os Antecedentes da Interseccionalidade. Revista Estudos Feministas, Florianópolis, v. 28, n. 1, p. 1-12, 2020.

LOURO, G. L. O currículo e as diferenças sexuais e de gênero. In: COSTA, M. V. O currículo nos limiares do contemporâneo. Rio de Janeiro: DP\&A, 2006.

NÓVOA, A. Formação de professores e profissão docente. In: NÓVOA, A. (Org.). Os professores e a sua formação. Lisboa: Publicações Dom Quixote, 1995.

PACHECO, A. C. L. Mulher negra: afetividade e solidão. Salvador: EDUFBA, 2013.

ROZAS, L. B. Cotas para negros nas universidades públicas e a sua inserção na realidade jurídica brasileira - por uma nova compreensão epistemológica do princípio constitucional da igualdade. Dissertação de Mestrado. Programa de Pós-Graduação em Direitos Humanos da Faculdade de Direito da Universidade de São Paulo, 2009.

SANTOS, M. V.; MOLINA NETO, V. Aprendendo a ser negro: a perspectiva dos estudantes. Cafajeste. Pesqui. São Paulo, v. 41, n. 143, p. 516-537, 2011.

SCOTT, J. Gênero: uma categoria útil para análise histórica. In: HOLLANDA, H. B. (org.). Pensamento feminista: conceitos fundamentais. Rio de Janeiro: Bazar do Tempo, 2019.

SEGATO, R. L. Cotas: por que reagimos? Revista USP, São Paulo, nº 68, p. 76-87, 2006.

SILVA, P. B. G. Negros na universidade e produção do conhecimento. In: SILVA, P. B. G.; SILVÉRIO, R. (org.). Educação e ações afirmativas: entre a injustiça simbólica e a injustiça econômica. Brasília: Instituto Nacional de Estudos e Pesquisas Educacionais Anísio Teixeira, 2003.

SILVA, P. B. G.; BARBOSA, L. M. A. Pensamento Negro em Educação no Brasil: expressões do Movimento Negro. São Carlos: EDUFSCar, 1997.

TARDIF, M. Saberes Docentes e Formação Profissional. Petrópolis: Vozes, 2014.

TELES, T. R. Política De Cotas Do Ensino Superior Brasileiro: Uma Análise Percuciente In Faciem Do Princípio Constitucional da Igualdade. Constituição, Economia e Desenvolvimento: Revista da Academia Brasileira de Direito Constitucional. Curitiba, vol. 7, n. 12, p. 233-255, jan-jun. 2015. 